\title{
Vozes de mulheres migrantes não apenas em 8 de março
}

\author{
Elizabeth Ruano*
}

\section{Introdução}

Neste relato problematizo o caráter trivial que pode assumir a noção de representação em contextos migratórios. Para tanto, retomo a minha participação em condição de representante das mulheres migrantes na mesa ${ }^{1}$ de abertura do "Seminário Regional de Cooperação Sul-Sul sobre a Proteção dos Direitos dos Trabalhadores e Trabalhadoras Migrantes na América Latina e no Caribe" ${ }^{2}$, realizado em $8^{3}$ de março de 2016. Essa incursão esteve demarcada pela comemoração do dia internacional da mulher e se tratou de uma homenagem idealizada pela organização desse evento às mulheres migrantes. Atualmente alcançam mais de 111 milhões de mulheres, número que representa $48 \%$ do contingente global de migrantes no mundo.

Em contextos de feminização das migrações prevalece o silêncio ensurdecedor relegado sistematicamente às mulheres e às minorias, que raramente encontram espaço para se expressar (SILVEIRINHA, 2012). Nesse sentido, o convite para discursar nesse evento foi recebido como uma oportunidade ímpar de ter voz em um cenário internacional de debate sobre as migrações internacionais. No entanto, a elaboração do discurso implicou também em questionar a legitimidade dessa representação outorgada de cima para baixo. Assim, no discurso proferido optei por ecoar as narrativas de outras mulheres migrantes e acentuar a diversidade nos percursos, nos destinos individuais e nas estruturas sociais que reproduzem situações de vulnerabilidade feminina.

Contudo a questão da legitimidade da representação ficou em aberto. Mencionar durante um discurso pronunciado em um espaço hegemônico, enquanto arena que restringe a sua participação às migrantes em situação laboral precarizada, em condição de status migratório irregular e outras categorias que dão conta da complexidade das migrações femininas, não legitima o lugar de representação outorgado. Torná-las objeto do discurso, falar delas e por elas continua sendo um desdobramento da condição marginal delas nesses espaços (HERNÁNDEZ CASTILLO, 2014, jamais equivalente à sua presença e protagonismo nos seus projetos migratórios.

\footnotetext{
* Doutora em Ciências Sociais. Professora visitante do CEPPAC-UnB.

E-mail:elizabeth@unb.br
} 
É importante frisar que aqui analiso três narrativas que surgiram em contextos diferenciados. Como já explicitado, minha fala foi construída para corresponder às demandas do convite para participar do evento mencionado. Ditas demandas enquadram-se na minha condição de identidade multifacetada, como mulher migrante e estudiosa das migrações. O segundo discurso analisado também foi preparado pela sua autora tendo como foco o evento em questão, porém situações de ordem logística inviabilizaram a sua participação. 0 terceiro discurso foi colhido em situação de pesquisa acadêmica no contexto de um projeto recentemente concluído ${ }^{4}$. Os trechos aqui citados correspondem adaptações analíticas fundamentadas na autorização explicita das suas autoras para dito objetivo.

Conforme Couldry (2009), cada relato individual deve ser registrado e ouvido, no entendimento de que a história pessoal surge emaranhada com as histórias de outros. Revisito essas três narrativas na perspectiva da "voz como processo" (Couldry, 2010). Se trata de dar significação à vida de alguém e às suas condições, isto é, relatar a história promovendo outras narrativas.

A escolha dos discursos aqui analisados teve como critério destacar as diferenças no perfil e nas trajetórias dessas mulheres migrantes.

Quadro 1. Perfil das autoras das narrativas

\begin{tabular}{|c|c|c|c|c|}
\hline Nome $^{5}$ & Idade & Nacionalidade & Profissão & Status migratório \\
\hline Erika & 30 & Nigéria & Professora & Solicitante de refúgio \\
\hline Nilsa & 28 & Paraguai & Frentista & Visto permanente \\
\hline Elizabeth & 40 & Colômbia & Professora & Visto permanente \\
\hline
\end{tabular}

Fonte: autoria própria

Como traços comuns entre as autoras dos discursos aqui estudados se destaca o fato de serem mulheres, migrantes e trabalhadoras radicadas no Brasil $^{6}$. A nacionalidade, idade, profissão e status migratório são características que incidem no lugar dessas mulheres no país de destino (quadro 1). Nesse sentido, cabe questionar em que condições essas características incidem na possibilidade de se ter voz. No debate acadêmico, Couldry (2009) se questionou por que a voz importa? Para o autor, se ter voz é crucial para potencializá-la como agenciamento reflexivo. Essa potencialização somente ocorre quando o sujeito sabe que a sua voz pode interessar em determinadas situações.

\section{Vida em refúgio: a voz de Erika?}

Erika é uma mulher de trinta anos de idade, nascida na Nigéria onde atuava profissionalmente como professora. Conflitos de natureza sociopolítica no seu país de origem obrigaram-na a migrar e procurar o status como refugiada no 
Brasil, no ano de 2014. Na sua condição de solicitante de refúgio experimenta os desdobramentos do status migratório em caráter de provisoriedade e incerteza. O status atravessa todas as esferas da vida transformando-se em acirrada vulnerabilidade. Nos seguintes parágrafos, reproduzo sua voz destacando seu agenciamento reflexivo que aparece demarcado na importância e urgência da regularização do seu status como refugiada.

Segundo a sua comprensão:

Nós refugiados imigrantes, homens e mulheres, somos bastante diferentes dos outros imigrantes que se deslocaram ao Brasil buscando pastos mais verdes. Nós refugiados imigrantes viemos para buscar a proteção do Estado, porque outros expandiram suas proibições sobre nós. Nós, saímos do nosso país de origem sem nada em termos de coisas materiais. Viemos com as nossas mãos para cima, mostrando que não temos nada além de nossas vidas. Alguns de nós foram mentalmente devastados, emocionalmente agredidos, financeiramente despojados.

A voz de Erika enfatiza a vulnerabilidade dos solicitantes de refugio e a necessidade de que o Estado brasileiro extenda proteção especial para eles:

Viemos para encontrar socorro, para ter certeza e razões para viver, mas infelizmente enfrentamos reveses. Não posso negar alguma acolhida que tem sido útil, mas ainda há muitas brechas. Até agora, a maioria de nós que viemos em 2014, estamos ainda por conhecer o destino no que diz respeito ao pedido de refúgio. As mulheres sofrem a pior parte, algumas caíram nas mãos de companheiros sem coração que se aproveitaram da vulnerabilidade. Algumas encontram-se grávidas sem que fosse seu próprio desejo. Algumas sofrem todos os tipos de doenças.

O trecho acima demarca algumas caracteristicas que dizem respeito a especificidade da feminização das migrações. Essas vivências atualizam as evidências divulgadas pelo informe do Comitê das Nações Unidas para a Eliminação da Discriminação contra a Mulher (CEDAW, sigla em inglês) mediante as quais se denunciou a predominância do assédio e abuso sexual contra as migrantes, em especial aquelas em situação irregular de documentação (CEDAW, 2008).

No seu relato, Erika ainda aponta dificuldades cotidianas que se tornam empecilhos incortornaveis dada a dificuldade para a inserção no mercado de trabalho. Segundo Erika, 
a maioria de nós não temos onde reclinar a cabeça. Pessoalmente, quando solicito uma acomodação, em várias ocasiões me foi dada uma carta de recomendação [...] As dores que eu tenho não podem ser quantificadas. Tive um emprego como faxineira, então eu era capaz de gerar renda que, junto com outro refugiado, me permitiu alugar um apartamento que tive que deixar quando fui demitida em 10 de outubro de 2015. Passei por intimidações, desprezo e outros tipos de tratamento indigno até que finalmente fui demitida sem motivo razoável. Quando se trata de buscar oportunidades no mercado de trabalho, os refugiados passam por uma série de entrevistas e avaliações, mas muitas vezes sem sucesso. Tenho talento, sei cuidar dos cabelos e cozinhar pratos africanos, mas é tão difícil levantar algum capital para começar meu próprio negócio (ênfase minha).

Seu discurso enfatiza os obstáculos que os refugiados experimentam no tocante aos processos de mobilidade social. Isto é, apos dois anos de permanência no Brasil denota uma dinâmica de interiorização e aceitação dos retrocessos pessoais. No tocante a inserção laboral no país de destino, afirma que:

\begin{abstract}
Alguns de nós estamos prontos para assumir as oportunidades de emprego, sem importarmos com as nossas profissões que ficaram em casa. Mesmo que não seja nossa profissão, agora importa a "sobrevivência do mais apto". Penso que seria melhor se houvesse empregos ou tarefas para aqueles que não podemos falar fluentemente português, trabalhos que não precisem de muita comunicação. Enquanto isso, ir aprendendo a língua naturalmente. Não é aconselhável forçar o cérebro quando você está sob uma condição de intensa pressão porque vai ser um desperdício, especialmente quando se trata de adultos que têm que pensar em um monte de coisas: contas a pagar, sem comida, você não sabe o destino das crianças que você deixou para trás. Nossas vidas precisam de apoio. Temos muito para dar de volta à sociedade brasileira (ênfase minha).
\end{abstract}

O agenciamento que Erika exerce mediante seu relato, na sua condição de mulher nigeriana solicitante de refugio no Brasil, permite perfilar não apenas a legitimação da sua demanda pessoal por regularização do seu status migratório. Na sua voz é acionada frequentemente a ideia de um nós, um coletivo com o qual estabelece conexão identitária. Trata-se de uma representação exercida pela conciência da importância da sua voz diante da possibilidade de ser ouvida. 
Ela constroi um discurso que politiza seu lugar de fala a partir da reflexividade em torno da sua vivência e das experiencias de outros que compartilham dessa condição de vulnerabilidade.

\section{Migração para o trabalho: a voz de Nilsa8}

Nilsa é uma mulher paraguaia, de origem rural, de vinte e oito anos de idade. No seu relato afirma que iniciou seu percurso migratório no âmbito interno nacional quando ainda era menor de idade. Segundo ela, as condições socioeconômicas do seu país que se desdobram em dificuldades para a inserção no mercado de trabalho foram o que motivou sua decisão de migrar: "o problema no Paraguai é que não tem fonte de trabalho, especialmente para nós mulheres. Mulher no sítio não pode. Aí como é que se faz? [...] Quando tinha 15 anos sai da minha casa e fui para a capital [Assunção], trabalhava e conseguia me manter sozinha".

Neste caso, além da procura por um emprego a gravidez se coloca como mais uma motivação para emprender seu projeto de migração internacional:

Quando eu engravidei eu vim. Meu filho nasceu aqui no Brasil [...] Trabalhava como empregada em casa de família, deixava ele na creche, aí eu fui trabalhando, trabalhando [...] Nessa época, falava muito pouco com minha família. $E$ eu chorava muito, muito. Não podia falar com eles, era caro ligar para lá [Paraguai] (grifo meu).

Diferentemente das autoras dos outros dos relatos analisados, Nilsa é mãe soltera. Essa condição impõe desafios adicionais aos evidenciados pelas outras migrantes. Seu tempo é divido entre emprego, cuidados domésticos e deslocamentos. Nessa dificil equação, entre emprego e vida doméstica, é obrigada a delegar ao seu filho mais velho, de quinze anos, os cuidados do lar durante suas ausêcias:

Trabalho de segunda a sábado, das 8 às 16 horas. Meu emprego fica em outra cidade. Moro aqui porque o aluguel é mais em conta. Todo dia gasto uma hora no ônibus. Antes era pior, demorava 3 horas, tinha que acordar mais cedo, 05h30 horas devia estar dentro do ônibus [...] Tenho dois filhos menores. [...] Geralmente deixo a comida pronta para ele. Meu filho mais velho esquenta ou termina de fazer o almoço. Ele cuida da casa até eu voltar do serviço.

As responsabilidades como mãe competem asimetricamente com as exigências do emprego e remetem a outros riscos diante dos quais os filhos das 
migrantes são vulneraveis, como por exemplo o trabalho infantil, a exploração, a solidão, a impossibilidade de acesso à escola, dentre outros. Na dimensão social, o relato de Nilsa indica empecilhos enfrentados em relação a impossiblidade de aceder a espaços de lazer: [...] "gostaria de levar eles [filhos] para passear. É difícil, porque aqui perto não tem lugares bonitos, alías é perigoso, há muita violência".

Segundo Nilsa, morar longe do local de trabalho é uma decisão forçada pelo custo do aluguel. No entanto, o tempo dos percursos entre sua moradia e o local do serviço afeta outas dimensões da sua vida como o seu projeto de continuar estudando.

Eu pretendia estudar para ver se eu conseguia outro trabalho, só que por enquanto estou parada. Faltam documentos para comprovar que cursei até quinta série. Como os documentos são muito caros, eu tive que fazer uma nova prova para determinar a série que eu poderia estudar. Voltar a estudar é dificil para mim. Eu trabalho fora e cuido dos meus filhos e da casa9 ${ }^{9}$. Não sei como dou conta (grifo meu).

Para Nilsa, seu projeto migratório é bem sucedido dado que arranjou um emprego estável, com cartera assinada, e obteve o visto de status permantente. Sobre o visto, relata o que conseguiu graças aos seus filhos nasceram no Brasil. Quanto ao emprego, ele é fruto de uma rede incipiente de relações no país de destino:

\footnotetext{
Quando cheguei ao Brasil comecei trabalhando em uma casa de família, cuidando de um idoso. Quando ele faleceu, minha patroa falou com o gerente de um supermercado. Contou a minha história. Eles me chamaram para entrevista e me contrataram para trabalhar na faxina. Fiquei dois anos como faxineira. Depois me transferiram para o setor das embalagens. Eu trabalho direitinho para eles não me mandarem embora (ênfase minha).
}

A referência à rede incipiente de relacionamentos se sustenta na afirmativa de Nilsa que revela: "não conheço ninguém". Quando questionada sobre as pessoas com as quais se relaciona, ela indica que seus contatos com nativos brasileiros se restringem ao ambito laboral, sem alcançar laços de proximidade. Similar situação acontece nas escolas dos filhos. Segundo afirmou, os vinculos menos distantes se constroem na igreja que frequenta. Essa fraca conexão social ganha maior complexidade quando se lembra que há 15 anos Nilsa mora no Brasil. 


\section{Migração e acesso à educação: a voz de Elizabeth ${ }^{10}$}

A minha experiência pessoal reflete a importância das políticas de internacionalização da educação superior e da flexibilização dos trâmites para regularizar os projetos migratórios femininos. O convênio multinacional para Estudantes, Convênio da CAPES, tornou possível a realização do mestrado e doutorado no Brasil. Meu envolvimento como estudiosa da migração iniciou em 2013, no entanto comecei a experimentar a migração desde os nove anos de idade. Três décadas se passaram desde a primeira vez que tive que deixar meus pais e o vilarejo onde nasci diante do acirramento do conflito armado na Colômbia. Isto é, experimentei a migração inicialmente no contexto interno do meu país.

Pensando nas dificuldades do projeto migratório internacional, há que destacar que o desconhecimento do idioma do país de destino acarreta limitações que incidem negativamente na inserção dos migrantes. O relato de Nilsa também pontua essa questão. Segundo ela, "minha língua é o guarani, as pessoas estranham quando falo, as pessoas sabem que não sou de aqui e ficam receosas". No meu caso, "experimentei as dificuldades no aprendizado da língua portuguesa e os estranhamentos com a cultura brasileira". Porém, minha inserção foi mediada e facilitada pelo convívio universitário que revela meu status demarcado pelo visto de estudante de pós-graduação.

Durante quase uma década de permanência no Brasil tenho sentido o peso dos custos das taxas e da consecução da documentação exigida como solicitante do visto de estudante e, posteriormente, do visto permanente pelo casamento com um brasileiro. Nesses anos enfrentei e continuo enfrentando entraves legais e burocráticos que dificultam o exercício pleno de direitos enquanto cidadã migrante em situação regular de documentação.

Apesar das relatadas dificuldades na inserção social, econômica e produtiva como migrante regular, em 2014 consegui o primeiro carimbo na minha carteira de trabalho. Além de formalizar a minha condição de mulher trabalhadora migrante no Brasil, a carteira de trabalho me proporcionou dignidade e confiança. Nesse sentido, destaco que as políticas de emprego e de formação profissional e cidadã constituem, sem dúvida, uma estratégia eficaz de promoção dos direitos para as mulheres migrantes.

\section{Repensando o agenciamento reflexivo a partir de vozes femininas migrantes}

Este relato surgiu do meu incômodo diante do status de representação das mulheres migrantes que me foi concedido no âmbito do "Seminário Regional de Cooperação Sul-Sul sobre a Proteção dos Direitos dos Trabalhadores e Trabalhadoras Migrantes na América Latina e no Caribe", realizado em Brasília, em março de 2016. Escrever estas linhas evidenciou que a pesar de se tratar 
de uma representação outorgada de cima para baixo, a politização do lugar de fala, no meu caso como pesquisadora e militante na defesa dos direitos dos migrantes, remete ao agenciamento reflexivo em exercício. É nessa lógica que busco potencializar a visibilidade de outras vozes sem deixar de problematizar as armadilhas da mediação na minha condição acadêmica.

A estratégia analítica de colocar três relatos diferenciados em diálogo permitiu explorar a polifonia das vozes femininas em contextos migratórios. Se buscou problematizar o silêncio distinguindo os espaços de voz. Se entende que a participação de uma mulher migrante em um evento sem migrantes que discutiu políticas para esse segmento social constitui um âmago de participação política direta. Âmago porque evidenciou a ausência dos atores principais nesses espaços, confirmando o silenciamento questionado. Contudo, "dar" voz à outras migrantes neste trabalho acadêmico é um mecanismo que se traveste de visibilidade.

Ciente de que nos contextos migratórios as mulheres somos sistematicamente relegadas ao silêncio e que raramente encontramos espaços para expressarmos, optei por relatar minha experiência em um espaço comemorativo do chamado dia da mulher. A opção de trazer outras vozes, confiadas a mim em espaços de pesquisa acadêmica, visou destacar a sua polifonia. Essas vozes não surgem singulares e descontextualizadas. Não dizem apenas sobre sentimentos pessoais, surgem atreladas a estruturas opressivas que lhes dão forma e contexto. Nessas vozes, a complexidade dos dilemas humanos é permeada por anseios, conquistas e planos pessoais. Os dramas cotidianos relatados dizem respeito a questões burocráticas, jurídicas, linguísticas e culturais que dificultam a inserção dos migrantes nos países de destino, e evidenciam fenômenos estruturais nos países de origem.

A pluralidade das vozes femininas poderia ecoar nos espaços institucionalizados, não apenas como ato proforma no marco da comemoração de oito de março. As vozes aqui citadas denotam que as lutas cotidianas das mulheres em geral, e das migrantes trabalhadoras em particular, têm como utopia a gestação de um presente digno em condições de igualdade e reconhecimento de direitos. Essas trajetórias confluem no anseio de mudança das condições de vulnerabilidade claramente elucidadas nas palavras de Erika. Porém, uma significativa parcela de mulheres migrantes encontra-se em situação irregular de documentação, aspecto que é determinante na inserção precarizada e na perpetuação do silenciamento. 


\section{Notas}

${ }^{1}$ Integrada pelo ministro do Tribunal Superior do Trabalho e membro da Comissão de Peritos em Aplicação de Normas Internacionais da OIT, Lélio Bentes Corrêa, o Secretário Nacional de Justiça, Beto Vasconcelos, e o Diretor da Organização Internacional do Trabalho (OIT) no Brasil, Peter Poschen, a representante do ministério da Segurança Nacional de Trinidade e Tobago, Cheryl Ann, a sindicalista da Central Unitária de Trabajadores do Chile, Patrícia Coñoman, a representante da Costa Rica, Valentina Vives e por mim em qualidade de migrante e pesquisadora.

${ }^{2}$ Evento realizado em Brasília, entre 8 e 10 de março de 2016, com a participação de especialistas internacionais e delegações tripartites de governos e de organizações de empregadores e trabalhadores de Argentina, Brasil, Costa Rica, Chile e Trinidad e Tobago, objetivando a troca de informações e experiências sobre migração laboral.

${ }^{3}$ Nessa data é habitual a promoção da reflexão sobre os fenômenos sociais que sofrem as mulheres. Segundo a ONU, em 2015 uma de cada três mulheres foi vítima de violência além de discriminação por gênero, origem étnica, profissão, nacionalidade ou estatuto migratório. De outro lado, a disparidade salarial se tornou estrutural nos mercados edificados no patriarcado e no machismo institucional (GENTILI, 2016).

4 "Migrantes Paraguaios no Distrito Federal", realizada entre maio e dezembro de 2015. Objetivou explorar qualitativamente o dito fluxo migratório. Desenvolvida pelo Centro Scalabriniano de Estudos Migratórios (CSEM).

${ }^{5}$ Correspondem aos nomes reais das migrantes autoras dos relatos em análise, foi concedida autorização para esse propósito.

${ }^{6}$ Segundo a OIT (2016), 67 milhões de trabalhadores migrantes no mundo são mulheres, aproximadamente $28 \%$ desse total migraram desde as Américas. $53 \%$ dos migrantes em idade ativa (entre 20 e 64 anos) são mulheres originárias do continente americano. Segundo dados do Obmigra, entre o ano 2000 e 2014, o Brasil registrou um crescimento de $126 \%$ de trabalhadores migrantes. A proporção média de mulheres migrantes trabalhadoras no período correspondeu a $29 \%$.

${ }^{7}$ Relato encaminhado por e-mail, 6/03/2016, versão original redigida em inglês. Os paragráfos citados textualmente são resultado da tradução livre.

${ }^{8}$ Conversa informal realizada em Santa Maria (DF), 18/06/2014.

${ }^{9} \mathrm{Na}$ atual divisão sexual do trabalho, os cuidados, incluindo a provisão de bem-estar físico, afetivo e emocional, são realizados principalmente por mulheres. Nos países de origem e de destino das migrantes aqui citadas, as estatísticas oficiais confirmam que esse trabalho se enquadra habitualmente como não remunerado, sendo realizado majoritariamente por mulheres. No Brasil, as mulheres despendem em média 26,6 horas semanais realizando afazeres domésticos, enquanto o público masculino dedica 10,5 horas. As mulheres que trabalham fora do lar dedicam 22 horas, os homens desempregados 12,7 horas (IPEA, 2012). $\mathrm{Na}$ Colômbia, as mulheres dedicam em média 7, 23 horas e os homens 3,10 horas por dia no trabalho doméstico não remunerado (COLOMBIA, 2013). O Paraguai ainda carece de dados oficiais. Somente em 2015, o Ministério da Mulher, em parceria com a Comissão Econômica para América Latina (CEPPAL), iniciou ações de transferência e apropriação de metodologias visando mensurar o trabalho doméstico não remunerado. Na Nigéria, segundo um informe de USAID (2012), a maioria das mulheres dedica seu tempo ao trabalho doméstico não remunerado. Apenas $29,5 \%$ das nigerianas trabalham em espaços particulares.

${ }^{10}$ Estrato do discurso proferido no citado seminário. 


\section{Referências}

CEDAW. General recommendation No. 26 on women migrant workers. CEDAW/C/2009/ WP.1/R. 5 December 2008.

Disponible en:

http://www2.ohchr.org/english/bodies/cedaw/docs/GR_26_on_women_migrant_ workers_en.pdf

Acceso en 03.07.2015

COULDRY, Nick. Rethinking the politics of voice. Continuum: Jornal of Media \& Cultural Studies. Vol. 23, no4, August/2009, pp. 579-582.

COULDRY, NICK. Why voice matters: Culture and Politics after Neoliberalism. London: Sage, 2010.

CRISTALDO, Heloisa. Seminário discute direitos dos trabalhadores migrantes na América Latina.

Disponível em: https://nacoesunidas.org/oit-ministro-do-trabalho-participa-de-homenagem-as-mulheres-migrantes-em-seminario-no-dia-internacional-da-mulher/ Acesso em 9/3/2016.

COLÔMBIA - Departamento Administrativo Nacional da Eestadística-DANE. Cuenta satélite de la economía del cuidado. Boletin Técnico. Bogotá: DANE, 2012. 17 p.

GENTILI. Pablo. Mujeres latinoamericanas: voces en la lucha por la igualdad. Contrapuntos/ El País.

Disponível em: http://blogs.elpais.com/contrapuntos/2016/03/mujeres-latinoamericanas-voces-en-la-lucha-por-la-igualdad.html

Acesso em 9/3/2016.

HERNÁNDEZ, Rosalva Castillo. Entre el etnocentrismo feminista y el esencialismo étnico: las mujeres indígenas y sus demandas de género. In: ESPINOSA, Yuderkys miñoso; GÓMEZ, Diana Correal; OCHOA, Karina Muñoz (Ed.). Tejiendo de otro modo: Feminismo, epistemología y apuestas descoloniales en Abya Yala. Popayán: Editorial Universidad del Cauca, 2014. pp. 309- 324.

ILO Global estimates of migrant workers and migrant domestic workers: results and methodology / International Labour Office - Geneva: ILO, 2015, 118 p.

IPEA - Instituto de Pesquisa Econômica Aplicada. Trabalho para o mercado e trabalho para casa: persistentes desigualdades de gênero. Comunicado $n$ ㅇ 149. Brasília: IPEA, 2012. 18 p.

OIT - Organização Internacional do Trabalho. Ministro do Trabalho participará de homenagem às mulheres migrantes em seminário no Dia Internacional das Mulheres. Disponível em: http://www.ilo.org/brasilia/noticias/WCMS_458082/lang--pt/index.htm Acesso em 9/3/2016.

SILVEIRINHA, Maria João. O som do silêncio: a questão da voz nas sociedades neoliberais em crise. In: SÁ, Alexandre; PEIXINHO, Ana; CAMPONEZ, Carlo. Aprofundar a crise: olhares multidisciplinares. Coimbra: Imprensa da Universidade de Coimbra, 2012. 266 p.

USAID. Gender in Nigeria Report 2012: Improving the Lives of Girls and Women in Nigeria. 2012. 99 p.

Disponível em:

https://www.gov.uk/government/uploads/system/uploads/attachment_data/ file/67333/Gender-Nigeria2012.pdf

Acesso em 9/3/2016. 